\title{
Shade changing effectiveness of plasdone and blue covarine-based whitening toothpaste on teeth stained with chlorhexidine and black tea
}

\author{
Vania Bergesch ${ }^{1}$, Flávio Henrique Baggio Aguiar ${ }^{2}$, Cecilia Pedroso Turssi ${ }^{1}$, \\ Fabiana Mantovani Gomes França ${ }^{1}$, Roberta Tarkany Basting ${ }^{1}$, \\ Flávia Lucisano Botelho Amaral ${ }^{1}$
}

Correspondence: Dr. Flávia Lucisano Botelho Amaral

Email: flbamaral@gmail.com

\author{
'São Leopoldo Mandic Institute and Research Center, \\ Campinas, São Paulo, Brazil, \\ ${ }^{2}$ Restorative Dentistry, Piracicaba School of Dentistry, \\ UNICAMP, Piracicaba, São Paulo, Brazil
}

\section{ABSTRACT}

Objective: This study evaluated the effectiveness of toothbrushing with whitening toothpaste in altering the shade of stained human enamel. Materials and Methods: Thirty fragments of human enamel, stained with chlorhexidine/black tea underwent 1000 and 5000 brushing cycles (BC) with ( $n=10)$ : PLS (Gel Dental Day, Bitufo), Close Up White Now, Unilever (COVB) and regular (Gel Dental Night, Bitufo) toothpaste. Images were taken before staining (baseline), after staining (STN) and following 1000 and $5000 \mathrm{BC}$ and were analyzed using the CIELAB parameters $(\Delta \mathrm{E}, \Delta \mathrm{b}$ and $\Delta \mathrm{L})$. Statistical Analysis Used: Data were submitted to two-way ANOVA ( $\alpha=0.05$ ). Results: $\triangle \mathrm{E}$ was higher from STN to baseline; $1000 \mathrm{BC}$ to $\mathrm{STN}$ and $5000 \mathrm{BC}$ to STN $(P<0.001)$. Significant differences in $\Delta \mathrm{b}$ values were found from $1000 \mathrm{BC}$ to STN and $5000 \mathrm{BC}$ to STN. For COVB, greater $\Delta \mathrm{L}$ was observed from $1000 \mathrm{BC}$ to $\mathrm{STN}$, what differed statistically from the regular toothpaste $(P<0.05)$. There was no difference between toothpaste when $\Delta \mathrm{L}$ was calculated from $5000 \mathrm{CB}$ to STN. Conclusions: Toothpaste containing COVB or PLS in association with 5000 BCs showed similar effectiveness in changing enamel shade; but after the first 1000 toothbrushing cycles, the use of COVB toothpaste promoted higher lightness in stained enamel.

Key words: Dental enamel, tooth bleaching, toothpaste

\section{INTRODUCTION}

Tooth shade is the result of a combination of intrinsic coloration and the presence of accumulated extrinsic stains. ${ }^{[1]}$ Extrinsic staining has been related to several factors, including smoking, high tea, and coffee intake and the use of cationic chemicals, such as chlorhexidine in some mouthwashes. ${ }^{[1,2]}$ Treatment options to eliminate or reduce tooth staining vary from simple prophylaxis to the use of bleaching agents. ${ }^{[3]}$ Several companies have

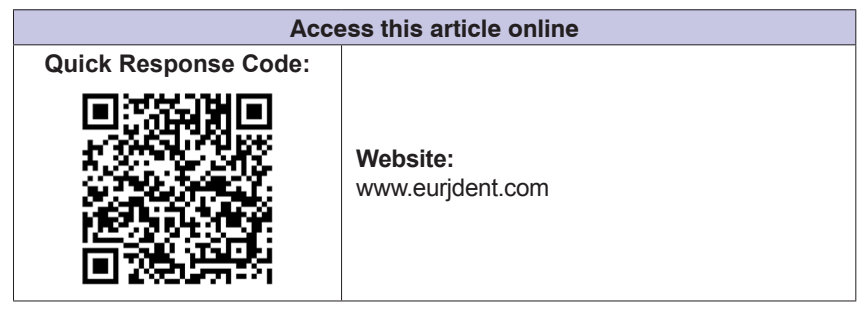

developed simpler and more easily accessible products for patients, such as whitening toothpaste that remove or prevent the formation of extrinsic pigments, aiming to meet the ever-growing demand for whiter teeth. ${ }^{[4]}$

The effect of such toothpaste is seen when abrasive particles are incorporated into the formula, which

This is an open access article distributed under the terms of the Creative Commons Attribution-NonCommercial-ShareAlike 3.0 License, which allows others to remix, tweak, and build upon the work non-commercially, as long as the author is credited and the new creations are licensed under the identical terms.

For reprints contact: reprints@medknow.com

How to cite this article: Bergesch V, Baggio Aguiar FH, Turssi CP,
Gomes França FM, Basting RT, Botelho Amaral FL. Shade changing
effectiveness of plasdone and blue covarine-based whitening
toothpaste on teeth stained with chlorhexidine and black tea. Eur J Dent
2017;11:432-7.
DOI: $10.4103 /$ ejd.ejd_97_17


mechanically removes both acquired pellicle and extrinsic stains. ${ }^{[5]}$ Nonetheless, excessive abrasiveness, as measured by radioactive dentin abrasion (RDA), may cause significant loss of tooth structure. ${ }^{[6,7]}$

On the other hand, chemical agents, including enzymes, detergents, oxygen-releasing substances (such as hydrogen peroxide), have been incorporated into toothpaste to chemically reduce/inhibit extrinsic staining. ${ }^{[4]}$ Polyvinylpyrrolidone, a povidone-based polymer, has also been added to toothpaste and has been demonstrated to be effective in inhibiting the adsorption of pigments onto dental tissues. ${ }^{[5]}$ Plasdone, or crospovidone, another povidone-based polymer, has recently been added to toothpaste and mouthwashes. However, its effectiveness in removing extrinsic pigments has not yet been evaluated.

Whitening toothpaste also utilizes optical illusion, via the addition of bluish colourings, such as blue covarine, to make the teeth appear brighter. Particles of blue covarine have been reported to accumulate on the enamel, generating an optical change (from yellow to blue) subsequently making the teeth look visually brighter. ${ }^{[8,9]}$

Some studies have tested the effectiveness of bleaching products by artificially staining the tooth structure using the chlorhexidine/black tea staining, which can be applied to enhance stains and allow comparisons between toothpaste. ${ }^{[10,11]}$

Given the scarcity of studies investigating the effectiveness of whitening toothpaste, especially those containing plasdone and blue covarine, the aim of this study was to evaluate the shade change induced by toothpaste containing these chemicals on brushing teeth that have been extrinsically stained with chlorhexidine and black tea.

\section{MATERIALS AND METHODS}

\section{Experimental design}

This in vitro study was designed based on the following factors:

1. Type of whitening agent present in toothpaste, on three levels:
a. Plasdone (Crospovidone) - Gel Dental Day (Bitufo, Brazil)
b. Blue covarine-CloseUp WhiteNow (Unilever, Brazil)
c. No whitening agent - Gel Dental Night (Bitufo, Brazil).

2. Shade change evaluation period, on four levels:

a. Baseline-before staining with chlorhexidine and black tea

b. Poststaining-after staining with chlorhexidine and black tea

c. Post-1000 brushing cycles (BCs)

d. Post-5000 BCs.

The experimental units were composed of thirty fragments of human enamel, randomly divided into three groups, according to the toothpaste used $(n=10)$. The quantitative response variable was the shade values, as measured using the CIELAB system, with the parameters $\Delta \mathrm{E}$ and $\Delta \mathrm{L}$. Table 1 describes the toothpaste tested in this study.

\section{Ethical aspects}

The present study was approved by the Local Ethics Committee in Research (CAAE 15672213.5.0000.5374).

\section{Preparation and staining of enamel fragments}

Freshly extracted teeth were cleaned with prophylactic paste using prophy brushes and stored in $0.1 \%$ thymol for up to 6 months. The teeth had their roots removed $2 \mathrm{~mm}$ below the cementoenamel junction using a water-cooled diamond saw (15 HC series, Buehler Ltd, Lake Bluff, Illinois, USA) in a sectioning machine (Isomet 1000 Precision Diamond Saw,

\begin{tabular}{|c|c|}
\hline $\begin{array}{l}\text { Toothpaste, manufacturer, } \\
\text { batch number }\end{array}$ & Composition \\
\hline $\begin{array}{l}\text { Gel day } \\
\text { Bitufo, Brazil } \\
\text { Batch number } 081692\end{array}$ & $\begin{array}{l}\text { Sodium fluoride (1100 ppm), } \\
\text { aqua, glycerin, sorbitol, } \\
\text { cellulose gum, xanthan gum, } \\
\text { methylparaben, propylparaben, } \\
\text { sodium saccharin, Cl 42051, } \\
\text { sodium bicarbonate, crospovidone, } \\
\text { hydrated silica, sodium lauryl } \\
\text { sulfate, cocamidopropyl betaine, } \\
\text { polyethylene homopolymer } \\
\text { and titanium dioxide }\end{array}$ \\
\hline $\begin{array}{l}\text { Gel dental night } \\
\text { Bitufo, Brazil } \\
\text { Batch number } 081692\end{array}$ & $\begin{array}{l}\text { Sodium fluoride ( } 1450 \mathrm{ppm} \text { ), aqua, } \\
\text { glycerin, sorbitol, cellulose gum, } \\
\text { xanthan gum, methylparaben, } \\
\text { propylparaben, sodium saccharin, } \\
\text { sodium monofluorophosphate, } \\
\mathrm{Cl} 42051 \text {, tetrasodium } \\
\text { pyrophosphate, triclosan, polymer, } \\
\text { calcium glycerophosphate, } \\
\text { hydrated silica, sodium lauryl } \\
\text { sulfate and disodium phosphate }\end{array}$ \\
\hline $\begin{array}{l}\text { Close up white now } \\
\text { Unilever } \\
\text { Batch number } 10222\end{array}$ & $\begin{array}{l}\text { Sorbitol, aqua, hydrated } \\
\text { silica, PEG-32, sodium lauryl } \\
\text { sulfate, cellulose gum, sodium } \\
\text { fluoride (1450 ppm), sodium } \\
\text { saccharin, PVM/MA copolymer, } \\
\text { trisodium phosphate, mica, Cl } \\
74160 \text { (blue pigment), Limonene }\end{array}$ \\
\hline
\end{tabular}


Buehler Ltd, Lake Bluff, Illinois, USA). Subsequently, the crowns were sectioned longitudinally in the buccolingual direction so that fragments measuring $3 \mathrm{~mm} \times 3 \mathrm{~mm}$ (length $\times$ height) were obtained from the interproximal surfaces. The enamel was exposed for staining by isolating the remaining surfaces with wax.

The specimens were stained according to the protocol adapted from Lath et al. ${ }^{[1]}$ Fifteen cycles were performed for:

1. Immersion in chlorhexidine for $2 \mathrm{~min}$ and rinsed in deionized water for $2 \mathrm{~min}$

2. Immersion in black tea solution $(1 \mathrm{~g}$ in $100 \mathrm{~mL}$ of water) at room temperature and rinsed in deionized water for $2 \mathrm{~min}$

3. For the last cycle, the specimens were left at room temperature for drying.

Immersion in saliva was not performed as Watts and $\mathrm{Addy}^{[1]}$ reported that dietary staining of chlorhexidine-treated teeth occurs in the absence of salivary pellicle.

\section{Toothpaste-aided brushing protocol}

A horizontal brushing technique was applied using a mechanical brushing simulator. The specimens were positioned parallel to the bristles of the toothbrushes (Oral B Indicator plus 35, Procter and Gamble, Jundiaí, SP, Brazil) and a standard load of $200 \mathrm{~g}$ was applied. Brushing movements were performed at 4.5 movements $/$ second at $37^{\circ} \mathrm{C}\left( \pm 0.5^{\circ} \mathrm{C}\right)$ in the presence of $3 \mathrm{~mL}$ of each toothpaste solution in deionized water in a 1:3 dilution (in weight). Two stages of 1000 and 5000 BCs were performed.

\section{Shade measurements}

The specimens were photographed at 4 different stages: Baseline- before chlorhexidine and black tea staining; poststaining- after chlorhexidine and black tea staining; after 1000 BCs-after brushing with different types of toothpaste; and after 5000 BCs.

A digital camera (Sony $\alpha$-200) equipped with a $105 \mathrm{~mm}$ lens was mounted on a distance-standardizing device at $40 \mathrm{~cm}$ from the object. Photographs from the enamel surfaces were taken with the camera set to manual, 1/125 shutter speed at F16, ISO 200, with the flash turned on.

The photographs were assessed using an image editing software(Adobe Photoshop 7.02i) to generatenumerical values according to the CIELAB system (Commission Internationale de $l^{\prime}$ Eclairage" -CIE). ${ }^{[12]}$ The color comparison was expressed in $\Delta \mathrm{E}$, represented by the formula

$\Delta \mathrm{E}=\left([\Delta \mathrm{L}]^{2}+[\Delta \mathrm{a}]^{2}+[\Delta \mathrm{b}]^{2}\right)^{1 / 2}$

The $\Delta \mathrm{s}$ were values was calculated between: (1) the stained condition and baseline (stained-baseline); (2) the condition of the fragments following 1000 BCs and baseline (post-1000 cycles-baseline); (3) the condition of the fragment after $5000 \mathrm{BCs}$ and baseline (post-5000 cycles-baseline), the difference in parameter values between the fragment condition after 5000 BCs and the condition after 1000 BCs (post-5000 cycles-1000 cycles); the fragment after 1000 BCs and the stained condition (post-1000 cycles-stained); the fragment after $5000 \mathrm{BCs}$ and the stained condition (post-5000 cycles-stained).

\section{Statistical analysis}

The data distribution fulfilled the requirements of normality and homogeneity of variance. The parameters $\Delta \mathrm{E}, \Delta \mathrm{L}$, and $\Delta \mathrm{b}$ were analyzed using repeated measures two-way Analysis of Variance. All multiple comparisons were calculated using the Tukey's test and the significance level adopted was $5 \%$. Statistical calculations were performed with SPSS version 20 (SPSS Inc., Chicago, IL, USA).

\section{RESULTS}

\section{$\Delta \mathrm{E}$ analysis}

The repeated measures (RM) two-way ANOVA revealed no effect on the interaction "toothpaste $\times$ time" $(P=0.39)$ or the factor "toothpaste" $(P=0.87)$. There was a significant effect of the factor "time" $(P<0.001)$. Higher shade changes were detected when $\Delta \mathrm{E}$ was calculated in the baseline-stained direction, in addition to the conditions "post-1000 BCs to stained" and "post-5000 cycles to stained", providing evidence that toothbrushing, regardless of the number of cycles (1000 or 5000 cycles), induced a considerable shade change when compared to stained enamel [Table 2]. When the $\Delta \mathrm{E}$ was calculated between "post- 1000 cycles to baseline" and "post-5000 cycles to baseline," an intermediate shade change was observed. However, it was not statistically significant.

\section{$\Delta \mathrm{L}$ analysis}

Data regarding $\Delta \mathrm{L}$ are summarized in Table 3. RM 2-way ANOVA revealed no effect of the factor "toothpaste" $(P=0.58)$. A significant effect was found for the factor "time" $(P<0.001)$. The interaction between the factors "toothpaste" and "time" showed 
a borderline effect $(P=0.05)$ and was postevaluated using the Tukey's test. Comparison of toothpaste in each period revealed that there was no significant difference in lightness when $\Delta \mathrm{L}$ was calculated between "stained to baseline". "post-5000 cycles to stained" and "post-5000 cycles to baseline," When $\Delta \mathrm{L}$ was calculated from "post-1000 cycles to stained", decreased lightness was observed for the regular toothpaste group, which was significantly different from the blue covarine group. In this period, plasdone toothpaste showed intermediate lightness values, which were not statistically different from the other groups.

For the blue covarine toothpaste, higher $\Delta \mathrm{L}$ was found when calculated between "post-1000 cycles to stained." Intermediate $\Delta \mathrm{L}$ values were found in the "post-5000 cycles-stained" and "post-1000 cycles-baseline" periods, which were not significantly different from each other but were distinct from the other periods studied. Negative $\Delta \mathrm{L}$ was found when calculated between "post- 5000 cycles-post- 1000 cycles" and "stained-baseline" periods.

For both plasdone and regular dentifrice, statistically higher $\Delta \mathrm{L}$ values were found in "post-1000 cycles-stained" and "post-5000 cycles-stained" periods. Negative $\Delta \mathrm{L}$ was found when calculated in "stained-baseline" periods.

\section{$\Delta \mathbf{b}$ analysis}

Data regarding $\Delta \mathrm{b}$ is summarized in Table 4. RM 2-way ANOVA revealed no significance on the interaction "toothpaste $\times$ time" $(P=0.919)$ or the factor "toothpaste" $(P=0.351)$. There was a significant effect of the factor "time" $(P<0.001)$. $\Delta \mathrm{b}$ was significantly higher when calculated from "stained" to "baseline." Intermediate values were found when $\Delta b$ was calculated between "post-1000 cycles and baseline" and "post-5000 cycles and baseline." In the period between "post-5000 cycles" and "post-1000 cycles," $\Delta \mathrm{b}$ was near zero, which was significantly different from the other periods. Finally, a significant difference and more negative $\Delta \mathrm{b}$ means were observed when calculations involved the periods "post-1000 cycles to stained," as well as "post-5000 cycles to stained," which were statistically similar to one another and different from the other groups.

\section{DISCUSSION}

Teeth shade change may be influenced by both intrinsic and extrinsic coloration, being the latter
Table 2: Mean and standard deviation of $\Delta E$ for the time periods tested

\begin{tabular}{lc}
\hline Period & Mean \pm SD \\
\hline Stained-baseline & $13 \pm 3^{\mathrm{A}}$ \\
1000 cycles-stained & $11 \pm 3^{\mathrm{A}}$ \\
5000 cycles-stained & $11 \pm 4^{\mathrm{A}}$ \\
5000 cycles-1000 cycles & $3 \pm 2^{\mathrm{B}}$ \\
1000 cycles-baseline & $6 \pm 2^{\mathrm{C}}$ \\
5000 cycles-baseline & $5 \pm 2^{\mathrm{C}}$ \\
\hline
\end{tabular}

Values followed by different uppercase letters denote significant difference between groups (significance level 5\%). SD: Standard deviation

\section{Table 3: Mean (standard deviation) of $\Delta \mathrm{L}$ for the} periods tested

\begin{tabular}{lccc}
\hline Period & \multicolumn{3}{c}{ Toothpaste } \\
\cline { 2 - 4 } & Blue covarine & Plasdone & Regular \\
\hline Stained-baseline & $-2(4)^{\mathrm{A}, \mathrm{d}}$ & $-2(3)^{\mathrm{A}, \mathrm{d}}$ & $-3(3)^{\mathrm{A}, \mathrm{C}}$ \\
1000 cycles-stained & $8(3)^{\mathrm{A}, \mathrm{a}}$ & $7(3)^{\mathrm{A}, \mathrm{B}, \mathrm{a}}$ & $5(3)^{\mathrm{B}, \mathrm{a}}$ \\
5000 cycles-stained & $5(4)^{\mathrm{A}, \mathrm{b}}$ & $6(2)^{\mathrm{A}, \mathrm{a}}$ & $6(3)^{\mathrm{A}, \mathrm{a}}$ \\
5000 cycle-1000 cycles & $-2(2)^{\mathrm{B}, \mathrm{d}}$ & $0(1)^{\mathrm{A}, \mathrm{d}}$ & $1(3)^{\mathrm{A}, \mathrm{b}}$ \\
1000 cycles-baseline & $6(2)^{\mathrm{A}, \mathrm{b}}$ & $4(3)^{\mathrm{A}, \mathrm{b}}$ & $2(3)^{\mathrm{B}, \mathrm{b}}$ \\
5000 cycles-baseline & $3(2)^{\mathrm{A}, \mathrm{C}}$ & $4(3)^{\mathrm{A}, \mathrm{b}}$ & $3(2)^{\mathrm{A}, \mathrm{b}}$ \\
\hline Values followed by different letters (uppercase in row and lowercase in
\end{tabular}

column) denote significant difference between groups (significance level $5 \%$ )

\begin{tabular}{lc}
$\begin{array}{l}\text { Table 4: Mean (standard deviation) of } \Delta \mathbf{b} \text { for the } \\
\text { periods tested }\end{array}$ \\
\hline Period & Mean $\pm S D$ \\
\hline Stained-baseline & $10 \pm 3^{\mathrm{A}}$ \\
1000 cycles-stained & $-7 \pm 3^{\mathrm{D}}$ \\
5000 cycles-stained & $-8 \pm 2^{\mathrm{D}}$ \\
5000 cycle-1000 cycles & $-1 \pm 1^{\mathrm{C}}$ \\
1000 cycles-baseline & $4 \pm 2^{\mathrm{B}}$ \\
5000 cycles-baseline & $3 \pm 2^{\mathrm{B}}$ \\
\hline
\end{tabular}

Values followed by different uppercase letters denote significant difference between groups (significance level 5\%). SD: Standard deviation

determined by the adsorption of pigments onto the tooth substrate, causing staining. ${ }^{[13]}$

Factors that play a role on extrinsic staining are brushing technique and smoking. ${ }^{[4]}$ In addition, staining observed clinically may be the result of the precipitation of antiseptics, such as chlorhexidine, or of chromogenic dietary substances, such as tea. ${ }^{[14]}$ The aim of the present study was, therefore, to apply a modified version of the tooth-staining model by Lath et al., ${ }^{[11]}$ where specimens were immersed in chlorhexidine and black tea. The main modification was that the specimens were not immersed in saliva before staining, since Addy and Roberts ${ }^{[15]}$ had already reported that saliva was not a determining factor on staining caused by chlorhexidine and black tea. In fact, the results from the present study demonstrated 
that $\Delta \mathrm{L}$ calculated between the stained and baseline periods resulted in negative values, thus showing that lightness was significantly lower in the stained condition while shade change $(\Delta \mathrm{E})$ and mean $\Delta$ b values were significantly higher in the stained- baseline condition, demonstrating that the staining model was valid.

Clinically, the dissatisfaction caused by teeth staining and the consequent rising demand for teeth whitening products have led to an increase in the market for such products. ${ }^{[4]}$ These products notably include whitening toothpaste, which can contain both chemical and abrasive agents to aid in extrinsic stain removal, or substances that visually alter color perception from yellow to blue, as in toothpaste containing blue

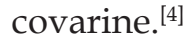

The present study evaluated the stain removal capacity of toothpaste containing a chemical from the N-vinylpyrrolidone- plasdone family, one containing the optical agent blue covarine, and finally, nonwhitening toothpaste with an abrasive component (control). No significant effect of the factor "toothpaste" was observed for $\Delta \mathrm{E}$ or $\Delta \mathrm{b}$, i.e., toothpaste performed similarly when analyzed within the tested periods.

When the toothpaste containing plasdone was launched, it promised to aid in the process of extrinsic stain removal. Claydon et al. ${ }^{[5]}$ performed a clinical study aimed at inhibiting chlorhexidine and black tea staining, through a toothpaste containing polyvinylpyrrolidone. The participants were instructed to use the toothpaste during the staining process, and not after the staining protocol as done in the present study. The authors reported that the polyvinylpyrrolidone (PVP) toothpaste prevented and controlled extrinsic staining. PVP is a synthetic polymer soluble in both water and noncationic agents, which is widely used in the pharmaceutical, textile, and food industries. ${ }^{[16]}$ Three types of PVP are available, namely, homopolymers, copolymers, and crosslinked PVP. [16] The latter can be obtained from a polymerization process known as "popcorn polymerization" [17] which results in an insoluble highly cross-linked PVP, denominated crospovidone. ${ }^{[18]}$ Crospovidone (or plasdone) is the main active ingredient in the Gel Dental Day toothpaste (Bitufo). In the medical industry, plasdone is used to manufacture films, such lubricant coatings. In addition, PVP forms a complex with catechins and other compounds that cause staining, removing them from the enamel. ${ }^{[19]}$ The present study evaluated only stain removal, therefore not permitting assessment of the stain-inhibiting effect of plasdone. The stain removal capacity of plasdone, however, was observed to be similar to other toothpaste, probably due to an abrasive effect. Despite not knowing the REA (radiotracer enamel abrasion) and the RDA of the toothpaste tested, all contained hydrated silica as their abrasive component, which may have accounted for their similar stain removal capacity. It is important to highlight that the Dental Day Gel also contained sodium bicarbonate, while the Dental Night Gel also contained tetrasodium pyrophosphate.

Shade change of tooth substrates relating to the use of toothpaste containing silica and blue covarine has been reported. ${ }^{[20]}$ Despite the latter having been shown to adhere to the tooth surface, creating an illusion of whiter teeth ${ }^{[4,8]}$ without staining composite resin and glass ionomer restorations. ${ }^{[21]}$ For the $\Delta \mathrm{L}$ parameter, the interaction between "toothpaste" and "time" factors showed that the blue covarine toothpaste yielded the best performance than the regular paste after 1000 brushing strokes, even though lightness was not significantly different between toothpastes after 5000 BCs. Considering silica as an abrasive agent, Joiner et al.$^{[8]}$ evaluated the abrasiveness of a silica-based toothpaste containing blue covarine, in addition to a whitening toothpaste containing silica, on both enamel and dentin. They concluded that the blue covarine toothpaste did not differ from the whitening toothpaste in terms of abrasiveness and enamel stain removal, perhaps due to their similar abrasive agents, as mentioned previously. It has been reported that whitening toothpaste that contains hydrated silica, with a few exceptions, are considered as the most abrasive. This may explain their similar capacity for tooth shade change when compared to the other products tested in the present study since all three contain that substance in their formula. ${ }^{[22]}$

Similarly to the results of the present study, Torres et al. ${ }^{[19]}$ tested the effectiveness of mouthwashes and toothpaste in enamel shade change, following staining by coffee, and observed no significant difference in terms of shade change between a PVP mouthwash (Plasdone K-29/32), a toothpaste containing blue covarine and a conventional fluoride toothpaste. It has been speculated that the short time in which the toothpaste is in contact with the teeth is not sufficient for the substances to act to remove stains chemically or to change shade. ${ }^{[23]}$

The present study evaluated enamel specimens postbrushing, after 1000 and 5000 BCs. Goldstein 
and Lerner ${ }^{[24]}$ reported that 1 year of brushing in vivo is the equivalent to $10,000 \mathrm{BCs}$ in vitro. Therefore, 5000 cycles would correspond to 6 months of brushing, while 1000 cycles to approximately 1 month. The present study demonstrated that, regardless of the toothpaste used, $\Delta \mathrm{E}$ and $\Delta \mathrm{b}$ were significantly altered when such parameters were calculated from $1000 \mathrm{BCs}$ to the stained substrate condition; however, no significant shade change was observed from 1000 to 5000 toothbrushing cycles. In the particular case of blue covarine toothpaste and the $\Delta \mathrm{L}$ parameter, higher lightness was observed following the first 1000 toothbrushing cycles. Therefore, it can be speculated that as the enamel was stained by extrinsic pigmentation, which in turn was weakly adhered to the enamel, 1000 cycles were sufficient to remove stains. Alshara et al. ${ }^{[25]}$ also observed that the whitening effect was more pronounced immediately after the $1^{\text {st }}$ day of treatment when most enamel extrinsic surface stains were removed, whereas only minimal shade change was noticed in the subsequent days.

Finally, when $\Delta \mathrm{b}$ and $\Delta \mathrm{E}$ were calculated from 5000 cycles or 1000 cycles to baseline, less shade alterations were observed, i. e., the shade parameters before staining (baseline) and after brushing were similar, thus indicating that the postbrushing shade may have recovered baseline values, as a result of the abrasion caused by the toothpaste.

\section{CONCLUSIONS}

Plasdone, blue covarine and regular toothpaste associated with 5000 toothbrushing cycles had similar performance in terms of enamel shade change; however, within the first 1000 cycles, the blue covarine dentifrice promoted increased lightness in stained enamel.

\section{Financial support and sponsorship \\ Nil.}

\section{Conflicts of interest}

There are no conflicts of interest.

\section{REFERENCES}

1. Watts A, Addy M. Tooth discolouration and staining: A review of the literature. Br Dent J 2001;190:309-16.
2. Walsh TF, Rawlinson A, Wildgoose D, Marlow I, Haywood J, Ward JM. Clinical evaluation of the stain removing ability of a whitening dentifrice and stain controlling system. J Dent 2005;33:413-8.

3. Bizhang M, Chun YH, Damerau K, Singh P, Raab WH, Zimmer S. Comparative clinical study of the effectiveness of three different bleaching methods. Oper Dent 2009;34:635-41.

4. Joiner A. Whitening toothpastes: A review of the literature. J Dent 2010;38 Suppl 2:e17-24.

5. Claydon NC, Moran J, Bosma ML, Shirodaria S, Addy M, Newcombe R. Clinical study to compare the effectiveness of a test whitening toothpaste with a commercial whitening toothpaste at inhibiting dental stain. J Clin Periodontol 2004;31:1088-91.

6. Giles A, Claydon NC, Addy M, Hughes N, Sufi F, West NX. Clinical in situ study investigating abrasive effects of two commercially available toothpastes. J Oral Rehabil 2009;36:498-507.

7. Franzò D, Philpotts CJ, Cox TF, Joiner A. The effect of toothpaste concentration on enamel and dentine wear in vitro. J Dent 2010;38:974-9.

8. Joiner A, Philpotts CJ, Alonso C, Ashcroft AT, Sygrove NJ. A novel optical approach to achieving tooth whitening. J Dent 2008;36 Suppl 1:S8-14.

9. Joiner A. A silica toothpaste containing blue covarine: A new technological breakthrough in whitening. Int Dent J 2009;59:284-8

10. Pontefract H, Courtney M, Smith S, Newcombe RG, Addy M. Development of methods to enhance extrinsic tooth discoloration for comparison of toothpastes 1 . Studies in vitro. J Clin Periodontol 2004;31:1-6.

11. Lath DL, Johnson C, Smith RN, Brook AH. Measurement of stain removal in vitro: A comparison of two instrumental methods. Int J Dent Hyg 2006;4:129-32.

12. Johnston WM. Color measurement in dentistry. J Dent 2009;37 Suppl 1:e2-6.

13. Joiner A. Tooth colour: A review of the literature. J Dent 2004;32 Suppl 1:3-12.

14. Addy M, Moran J. The formation of stain on acrylic surfaces by the interaction of cationic antiseptic mouthwashes and tea. J Biomed Mater Res 1984;18:631-41.

15. Addy M, Roberts WR. The use of polymethylmethacrylate to compare the adsorption and staining reactions of some cationic antiseptics. J Periodontol 1981;52:380-5.

16. Liu $\mathrm{X}, \mathrm{Xu} \mathrm{Y}, \mathrm{Wu} \mathrm{Z}, \mathrm{Chen} \mathrm{H}$. Poly (N-vinylpyrrolidone)-modified surfaces for biomedical applications. Macromol Biosci 2013;13:147-54.

17. Bühler V. Polyvinylpyrrolidone Excipients for Pharmaceuticals: Povidone, Crospovidone and Copovidone. Berlin Heidelberg: Springer; 2005.

18. Haaf F, Sanner A, Straub F. Polymers of N-vinylpyrrolidone: Synthesis, characterization and uses. Polym J 1985;17:143-52.

19. Torres CR, Perote LC, Gutierrez NC, Pucci CR, Borges AB. Efficacy of mouth rinses and toothpaste on tooth whitening. Oper Dent 2013;38:57-62.

20. Collins LZ, Naeeni M, Platten SM. Instant tooth whitening from a silica toothpaste containing blue covarine. J Dent 2008;36 Suppl 1:S21-5.

21. Ashcroft AT, Cox TF, Joiner A, Laucello M, Philpotts CJ, Spradbery PS, et al. Evaluation of a new silica whitening toothpaste containing blue covarine on the colour of anterior restoration materials in vitro. J Dent 2008;36 Suppl 1:S26-31.

22. Schemehorn BR, Moore MH, Putt MS. Abrasion, polishing, and stain removal characteristics of various commercial dentifrices in vitro. J Clin Dent 2011;22:11-8

23. Sharif N, MacDonald E, Hughes J, Newcombe RG, Addy M. The chemical stain removal properties of 'whitening' toothpaste products: Studies in vitro. Br Dent J 2000;188:620-4.

24. Goldstein GR, Lerner T. The effect of toothbrushing on a hybrid composite resin. J Prosthet Dent 1991;66:498-500.

25. Alshara S, Lippert F, Eckert GJ, Hara AT. Effectiveness and mode of action of whitening dentifrices on enamel extrinsic stains. Clin Oral Investig 2014;18:563-9. 